\title{
Atypical ganglioneurocytoma: case report and review of literature
}

\author{
Javed Khader Eliyas ${ }^{1}$, Peter Pytel ${ }^{2}$, Rimas V. Lukas ${ }^{3}$, Patrik Gabikian ${ }^{4}$ \\ 1. Section of Neurosurgery, University of Chicago, Chicago, IL, USA. 2. Departments of Pathology, University of Chicago, \\ Chicago, IL, USA. 3. Department of Neurology, University of Chicago, Chicago, IL, USA. 4. Department of Neurosurgery, \\ Kaiser Foundation Hospital, Los Angeles, CA, USA.
}

Correspondence: Javed Khader Eliyas. Address: University of Chicago Medical Center, Section of Neurosurgery, 5841 S. Maryland Ave, MC 3026, Chicago, IL, USA. E-mail: javkhel@gmail.com

Received: January 28, 2015

Accepted: May 3, 2015

Online Published: May 28, 2015

DOI : $10.5430 / c r c p . v 2 n 4 p 7$

URL: http://dx.doi.org/10.5430/crcp.v2n4p7

\begin{abstract}
Extra-ventricular neurocytoma (EVN) is a distinct neuro-pathological entity that has received increasing attention as the routine use of immunohistochemical staining has helped to distinguish it from oligodendroglioma; its more common morphologic mimic. Ganglionic differentiation in parts of the tumor is common, hence lending the name of Ganglioneurocytoma. Generally considered as low-grade tumors, recent literature highlights clinical examples with atypical pathologic features that elevate the grade of these tumors to World Health Organization (WHO) grade III and portend a worse prognosis. Biological progression to a higher tumor grade, serially over time in the same patient, has not been previously described. We report a case of low-grade ganglioneurocytoma (WHO grade II) that recurred with increased proliferation index and atypical features (WHO grade III). This case illustrates the challenges involved in precise grading of these tumors. Also exemplified is the unpredictable potential of seemingly low-grade lesions. Gross total resection and routine follow-up are essential for optimum treatment, as EVNs are associated with worse prognosis than their intra-ventricular counterparts.
\end{abstract}

\section{Key words}

Cerebral neurocytoma, Extraventricular neurocytoma, Ganglioneurocytoma, Atypical extraventricular neurocytoma, MIB-1 proliferation index

\section{I ntroduction}

Neurocytomas are rare brain tumors classically located in the vicinity of the foramen of Monro. Since their first intra-ventricular description by Hassoun et al. in 1982, these tumors have also been reported in many extraventricular and extra-axial sites ${ }^{[1]}$. EVNs may comprise as much as $10 \%$ of all neurocytomas, and unlike the central (intraventricular) variant, glial or ganglionic differentiation has been noted more frequently in them ${ }^{[2]}$. Ganglioneurocytoma, a subtype of neurocytoma with ganglionic differentiation, initially described by Nishio et al., is considered a low-grade tumor without reports of histopathological grade progression ${ }^{[3,4]}$. In this report, we present a case of WHO grade II ganglioneurocytoma (with typical features) progressing into an atypical ganglioneurocytoma. Also reviewed is the relevant body of literature on ganglioneurocytoma with special emphasis on natural history and clinical progression. 


\section{Case history}

A 25-year-old right-handed gentleman presented with recurrent left frontal brain tumor. Five years prior to the current presentation, he was evaluated for headaches and new onset seizures at another institution. Magnetic resonance imaging (MRI) of the brain had revealed a cystic tumor in the left frontal lobe with a mural nodule (see Figure 1). At that time, he underwent gross total resection of this lesion. Pathological examination from the first surgery demonstrated well demarcated tumor consisting of small round or polygonal cells arranged in clusters and sheets (see Figure 2). Some of the more polygonal cells showed distinct ganglion cell differentiation on H\&E stained sections. No areas of necrosis or vascular proliferation were noted. Only scattered mitotic figures were identified ( $<1$ per 20 high-powered fields), and the MIB-1 proliferation index was less than $4 \%$ focally. Immuno-histochemical staining was strongly positive for synaptophysin while Neuronal Nuclei (NeuN) was minimally reactive. Tumor cells were negative for Glial Fibrillary Acidic Protein (GFAP) and other glial markers. Final pathological diagnosis of ganglioneurocytoma WHO grade II was made based on these features.

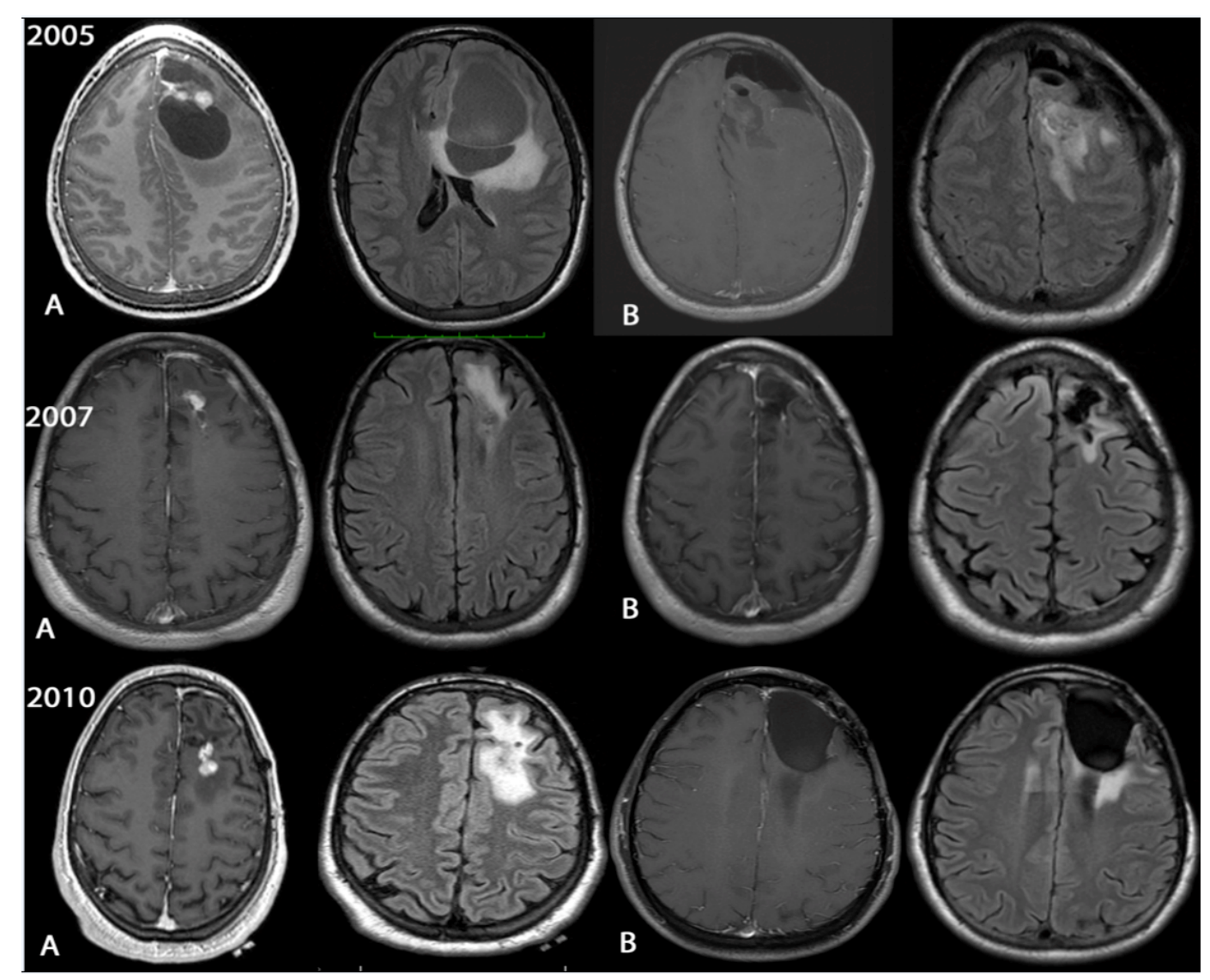

Figure 1. Pre-operative (A) and post-operative (B) MRI images, T1 with gadolinium contrast and FLAIR, respectively, in chronological order. The initial tumor in 2005 consisted of cystic lesion, an enhancing nodule with considerable surrounding edema (A1); immediate post-operative images show gross total resection (B1). In 2007, there was a small recurrence posterior to the surgical cavity (A1), which again underwent resection without complications (A2). For a second time the tumor recurred in 2010 (A3). We resected the tumor completely and irradiated the tumor bed. There has been no recurrence of tumor in 2.5 years since last resection (B3).

Although the patient remained neurologically well, routine surveillance imaging two years later (three years prior to current presentation) revealed tumor recurrence in the left frontal lobe (see Figure 1). This prompted a second surgery with resection of the enhancing mass. The pathologic specimen obtained from second surgery again showed similar morphologic features to those observed from the initial surgical specimen. However, mitotic figures were more numerous 
(3-4 mitoses per 20 high-powered fields) and the MIB-1 proliferative index was elevated at 10\% (see Figure 2). The final pathologic diagnosis remained ganglioneurocytoma. The patient recovered well from the second surgery, but despite the recurrence and increase in the proliferative index, he declined adjuvant treatment.
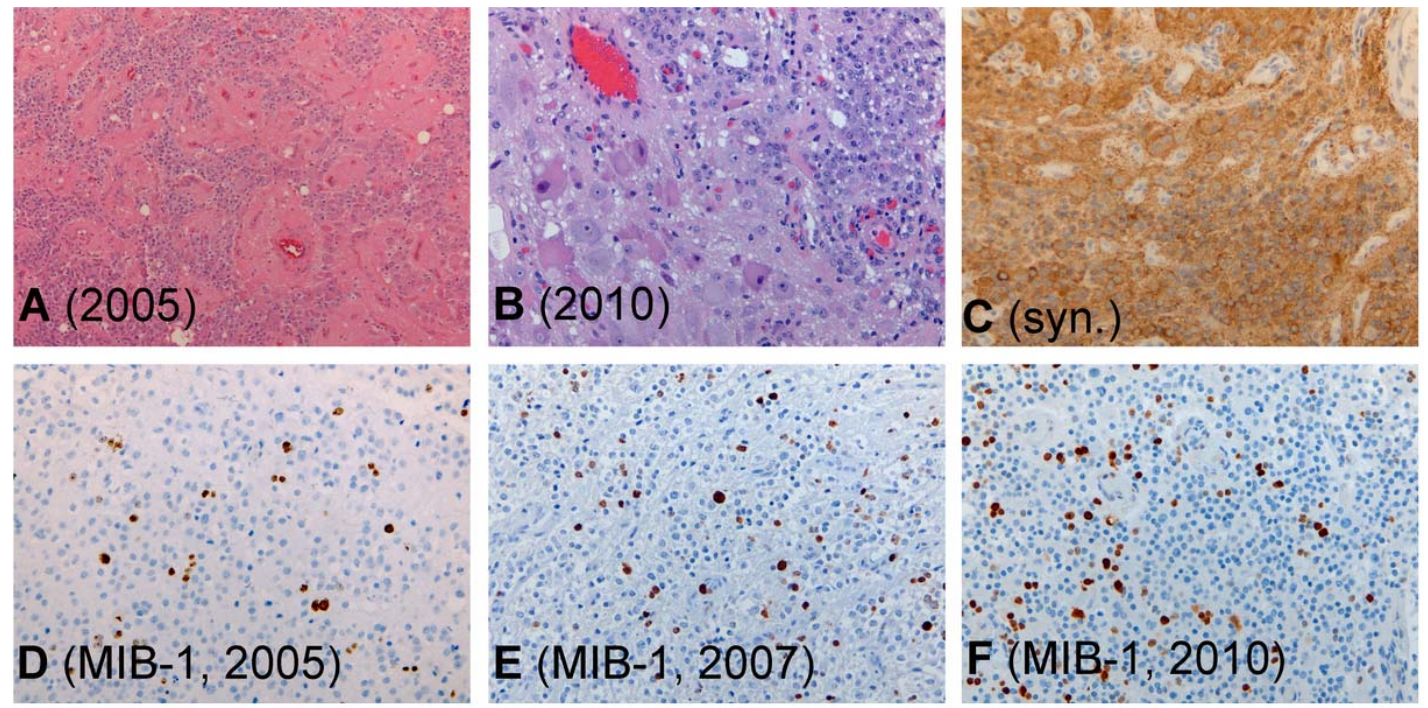

Figure 2. Representative histopathological sections demonstrating tumor progression over time. H\&E stain preparations show a cellular tumor consisting of numerous neurons and ganglion cells arranged in clusters, a hallmark of ganglioneurocytomas (A - magnification $\times 10 \& B$ - magnification $\times 20$ ). The tumor is strongly reactive for Synaptophysin $(C-$ magnification $\times 20$ ). MIB-1 staining of successive tumor resections shows progression of proliferative index over time from typical to atypical ganglioneurocytoma (D, E \& F - magnification $\times 20$ ).

Over the succeeding years, he underwent serial clinical and imaging surveillance and transferred his care to our institution. Three years after his second surgery, a new recurrence was noted as a nodule of MRI contrast enhancement (see Figure 1); because of lack of clinical sequelae, the patient chose no treatment. Recurrent seizures prompted another brain MRI - now four years after his second surgery and six years after initial presentation - that revealed a larger nodular tumor growth and mass effect (see Figure 1). As a result, the patient underwent a third craniotomy where a complete resection of tumor was achieved. He developed transient supplementary motor area syndrome post-operatively, but made a complete neurologic recovery within weeks. Histopathological examination of the tumor again revealed sheet-like arrangement of neurocytic cells with variable degrees of ganglion-cell differentiation (see Figure 2). Synaptophysin and Protein Gene Product (PGP) 9.5 staining were strongly positive, while reaction to NeuN was again weak. Electron microscopic studies also confirmed neuronal differentiation of the lesional cells. No necrosis or vascular proliferation was apparent but mitotic figures $(<2$ per 10 high-powered filed) were again noted. MIB-1 proliferation index was still elevated at $11 \%$. The final histopathologic diagnosis of this tumor specimen was atypical ganglioneurocytoma. Considering the biologic progression of the tumor and repeated clinical recurrence, the patient then underwent intensity-modulated radiotherapy equaling 54 Gy to the tumor bed. At 2.5-year follow-up from his third surgery, the patient remains well without neurologic deficits or evidence of tumor recurrence on neuroimaging. Given the patient's clinical course and pathologic progression, we plan routine imaging surveillance at six-month intervals, for the time being.

\section{Discussion}

Neurocytomas constitute less than $0.5 \%$ of all primary brain tumors but only a small subset are found in extraventricular locations (two-thirds of these are reported to be ganglioneurocytomas) ${ }^{[2,5-7]}$. Extra-ventricular ganglioneurocytomas have been reported in various sites including cerebral hemispheres, diencephalon, brainstem, spinal cord and skull base ${ }^{[2,8-10]}$. Within the cerebral hemispheres, they are more commonly found in the frontal lobe, similar to EVNs ${ }^{[11,12]}$. Patients with 
EVN usually present in middle age, especially in the third and fourth decades of life, while ganglioneurocytomas are often diagnosed in the second decade of life (see Table 1). No convincing sexual predilection exists though some series have reported slight female preponderance ${ }^{[11,13]}$. Hydrocephalus is usually associated with central neurocytomas, while extraventricular counterparts present frequently with seizures. The preponderance of location in the fronto-temporal regions might explain the stronger correlation between seizure activity and ganglioneurocytomas (see Table 1). EVNs have rarely been reported to present with intra-tumoral hemorrhage ${ }^{[14]}$. The natural history is one of slow clinical progression, as in most low-grade primary brain tumors. Patients often present with symptoms of hemispheric space occupying lesions such as seizures and motor deficits ${ }^{[15,16]}$.

Table 1. List of ganglioneurocytomas reported in the literature

\begin{tabular}{|c|c|c|c|c|c|c|c|}
\hline References & Age/Sex & Presentation & Location & $\begin{array}{l}\text { Atypical } \\
\text { Features }\end{array}$ & Treatment & Follow up & Recurrence \\
\hline $\begin{array}{l}\text { Nishio et al. }{ }^{[18]} \\
(1990)\end{array}$ & $30 / \mathrm{F}$ & Seizures & Left Frontal & No & STR + 45 Gy & 7 Years & None \\
\hline $\begin{array}{l}\text { Nishio et al. }{ }^{[19]} \\
(1992)\end{array}$ & $2 / F$ & Seizures & Left Frontal & No & STR & 2 Years & None \\
\hline $\begin{array}{l}\text { Nishio et al. }{ }^{[19]} \\
(1992)\end{array}$ & $41 / \mathrm{M}$ & Seizures & Right Temporal & No & STR & 2 Years & None \\
\hline $\begin{array}{l}\text { Nishio et al. }{ }^{[19]} \\
(1992)\end{array}$ & $3 / \mathrm{M}$ & Seizures & Right Frontal & No & STR & 2 months & None \\
\hline $\begin{array}{l}\text { Funato et al. }{ }^{[7]} \\
\text { (1997) }\end{array}$ & $11 / \mathrm{F}$ & Hemiparesis & Right Frontal & No & GTR & 18 months & None \\
\hline $\begin{array}{l}\text { Giangaspero et } \\
\text { al. }{ }^{\left[{ }^{[0]}\right.}(1997)\end{array}$ & & $\begin{array}{l}\text { Ganglionic } \\
\text { Differentiation }\end{array}$ & In $6 / 6$ & & & & \\
\hline $\begin{array}{l}\text { Teo et al. }{ }^{[27]} \\
\text { (1999) }\end{array}$ & $40 / \mathrm{F}$ & Hemiparesis & Right Frontal & Yes & STR + 60Gy & 30 months & 24 months \\
\hline $\begin{array}{l}\text { Teo et al. }{ }^{[27]} \\
\text { (1999) }\end{array}$ & $31 / \mathrm{M}$ & Seizures & $\begin{array}{l}\text { Right } \\
\text { Fronto-Temporal }\end{array}$ & No & STR (95\%) & 6 Years & In 4 Years \\
\hline $\begin{array}{l}\text { Teo et al. }{ }^{[27]} \\
\text { (1999) }\end{array}$ & $37 / \mathrm{M}$ & Seizures & Right Temporal & No & STR & 4 Years & In 2 Years \\
\hline $\begin{array}{l}\text { Teo et al. }{ }^{[27]} \\
(1999)\end{array}$ & $25 / F$ & Seizures & Left Frontal & Yes & $\begin{array}{l}\text { STR + } 59 \text { Gy + } \\
\text { BCNU }\end{array}$ & 13 months & None \\
\hline $\begin{array}{l}\text { Tortori-Donati } \\
\text { et al. }{ }^{[28]} \text { (1999) }\end{array}$ & $9 / F$ & Seizures & Right Frontal & No & GTR & 6 months & None \\
\hline $\begin{array}{l}\text { Biernet et al. }{ }^{[12]} \\
(2000)\end{array}$ & $12 / \mathrm{M}$ & Seizures & Left Frontal & Yes & GTR & Not reported & Unknown \\
\hline $\begin{array}{l}\text { Brat et al. } \\
(2001)\end{array}$ & & $\begin{array}{l}\text { Ganglionic } \\
\text { Differentiation }\end{array}$ & in $23 / 35$ & & & & \\
\hline $\begin{array}{l}\text { Shin et al. } \\
(2002)\end{array}$ & $23 / \mathrm{M}$ & Seizures & $\begin{array}{l}\text { Left } \\
\text { Parieto-Occipital }\end{array}$ & No & Not reported & Not reported & Not reported \\
\hline $\begin{array}{l}\text { Nishihara et al. } \\
{[17](2008)}\end{array}$ & $32 / \mathrm{F}$ & Seizures & Right Parietal & No & $\begin{array}{l}\text { STR + RT (dose } \\
\text { unknown) }\end{array}$ & Not reported & Not reported \\
\hline $\begin{array}{l}\text { Chou et al. } \\
\text { (2010) }\end{array}$ & $34 / \mathrm{M}$ & Seizures & Right Frontal & Yes & GTR & Not reported & Not reported \\
\hline $\begin{array}{l}\text { Ghosal et al. }{ }^{[8]} \\
\text { (2011) }\end{array}$ & $9 / \mathrm{M}$ & Headache & Left Fronto-Parietal & Yes & STR & Not reported & Not reported \\
\hline $\begin{array}{l}\text { Agarwal et al. }{ }^{[2]} \\
\text { (2011) }\end{array}$ & 19/M & & Left Paraventricular & No & $\mathrm{GTR}+\mathrm{RT}$ & 36 months & None \\
\hline $\begin{array}{l}\text { Agarwal et al. }{ }^{[2]} \\
\text { (2011) }\end{array}$ & $20 / \mathrm{M}$ & & Left Frontal & Yes & $\mathrm{STR}+\mathrm{RT}$ & 3 months & Unknown \\
\hline $\begin{array}{l}\text { Agarwal et al. }{ }^{[2]} \\
\text { (2011) }\end{array}$ & $35 / \mathrm{M}$ & & Left Fronto-Parietal & Yes & $\mathrm{STR}+\mathrm{RT}$ & 5 months & None \\
\hline Our Report & $19 / \mathrm{M}$ & Seizures & Left Frontal & Yes & GTR $\times 3+54$ Gy & 7 Years & 2 recurrences \\
\hline
\end{tabular}

Note. GTR - Gross total resection, STR - Subtotal Resection, Gy - Gray 
Imaging characteristics of ganglioneurocytomas consist of well-circumscribed cortical lesions with both solid and cystic components and occasional areas of calcification ${ }^{[17,18]}$. On brain Computerized tomography (CT), lesions appear hyperdense with irregular calcifications. MR imaging reveals isointense to hypointense lesions on T1-weighed sequences with heterogenous gadolinium enhancement. On T2-weighed sequences, these tumors can be isointense to hyperintense, and peritumoral edema can be appreciated in fluid attenuation inversion recovery images ${ }^{[7,17,18]}$. Rarely, these are dural based and take up contrast homogenously similar to meningiomas ${ }^{[19]}$. In cases with ganglionic differentiation, a cystic mass may be found with a mural nodule (see Figure 1). The solid component can have varying MR features, based on the cellularity and differentiation of the tumor. In MR spectroscopy, EVNs show increased choline and decreased (or absent) $\mathrm{N}$-acetyl aspartate, similar to intraventricular neurocytomas ${ }^{[20]}$.

Histopathologically, ganglioneurocytomas consist of small round or polygonal cells arranged in sheets, clusters, or ribbons. The nuclei are distinct and lack mitotic figures - except in cases of atypical tumors - while the cytoplasm is clear or eosinophilic. Frequently, these cells are embedded in a neuropil stroma that shows chicken-wire pattern of vascularization by hyalinised vessels ${ }^{[2,21]}$. With these features, the histomorphology can be similar to oligodendrogliomas. Preparation techniques can produce halos around the nuclei simulating oligodendrogliomas, although 1p and/or 19q deletions associated with oligodendrogliomas are absent ${ }^{[2]}$. EVNs can differentiate into either glial and/or ganglionic forms, but ganglionic differentiation is more common, especially in cerebral tumors ${ }^{[7,13]}$. Immunohistochemical staining often shows positivity for synaptophysin and NeuN while being negative for GFAP and p53. Occasional tumors with glial differentiation can be positive for GFAP or GFAP positivity could be due to entrapped astrocytes ${ }^{[22]}$. On electron microscopy, synapse-like structures are absent or sparsely distributed at the surface of tumor cell processes ${ }^{[23]}$. Atypical features, including nuclear pleomorphism, mitotic index $>3$ per high-power field, areas of necrosis, and/or vascular proliferation, are occasionally seen ${ }^{[7,19,24]}$. Recently, proliferation index in the form of MIB-1 labeling has been used to delineate more aggressive tumors, with a MIB-1 index greater than 2\%-5\% conferring atypical status in these tumors ${ }^{[25,26]}$. In the largest series on EVN by Brat et al., 31\% of tumors were atypical, while Furtado et al. in their review found atypical features in $27 \%$ of these tumors ${ }^{[7,11]}$. The current WHO classification of Central Nervous System (CNS) tumors recognizes neurocytomas as low grade (grade II) ${ }^{[5]}$. Correlation between ganglionic differentiation and atypicality of EVNs is inferable, due to clinical and pathological outcome such as in our patient. In the case series by Brat et al, 73\% of atypical EVNs exhibited ganglionic differentiation ${ }^{[7]}$.

Treatment is mainly surgical with good outcomes achieved after gross total resection. Post-operative radiation may reduce recurrences, especially in cases with atypical histopathology or residual tumor. Gross total resection (GTR) is an important factor in preventing or delaying recurrences. In the series by Brat et al., 11 out of 14 patients who underwent GTR developed no recurrence over a mean follow up period of 29 months ${ }^{[7]}$. In contrast, 10 out of 19 sub-total resection (STR) patients experienced tumor recurrence within 17 months ${ }^{[7]}$. Furtado et al. corroborate this finding in their review and further emphasize that atypical lesions manifested disease recurrence earlier than typical EVNs ${ }^{[11]}$.

Adjuvant radiotherapy is generally advocated for residual disease and atypical tumors. Rades et al. in their meta-analysis of atypical neurocytomas found a better outcome for incompletely resected tumors radiated post-operatively compared with incomplete resections that were not irradiated ${ }^{[27]}$. This increased benefit of improved overall survival and progression-free survival matched that of completely resected lesions (with or without radiation) ${ }^{[27]}$. The treatment dose ranges from 50-54 Gy of fractionated irradiation, analogous to radiotherapy treatment for other glial neoplasms. Other forms of radiotherapy; brachytherapy, hypofractionated treatment schemes, and stereotactic radiosurgery to the tumor bed or residual mass as alternatives in select cases, have not been studied or reported. The role of adjuvant radiotherapy for a typical EVN after GTR is unknown. However, there can be progression of pathology toward a more malignant phenotype in recurrences, sometimes in spite of GTR ${ }^{[28]}$. Given the rare incidence of EVNs or ganglioneurocytomas, the definitive role and timing of chemotherapy is not well established, with a tendency to reserve chemotherapy as a salvage option. Numerous chemotherapy regimens have been evaluated in the adjuvant and salvage setting for central neurocytomas with suggestion of benefit. Commonly employed regimens are often cisplatin/carboplatin and etoposide based, with addition of cyclophosphamide or ifosfamide as a third agent ${ }^{[29,30]}$. 


\section{Conclusions}

In the histopathologic spectrum of glioneuronal neoplasms, ganglioneurocytomas have been recognized as a subtype of neurocytomas with a predilection for extraventricular location, low-grade pathologic features, and generally good prognosis. However, because of limited long-term clinical data, potential for histopathologic uncertainty due to a lack of diagnostic markers, and recent reports indicating more aggressive clinical behavior, the presumed benign nature of these tumors is questionable. In this report, we present a detailed course of clinical and pathological progression observed in a ganglioneurocytoma patient over a seven-year period with serial histopathologic and imaging confirmation. This case presents a rare opportunity to study serial tumor progression in ganglioneurocytoma unaffected by adjuvant treatments over a long follow-up. In many brain tumors increased proliferative activity is a feature of higher WHO grade. In this case, the patient was recurrence free for three years after the second surgery, despite not receiving any adjuvant therapy. It is difficult to establish whether a ganglioneurocytoma with the described features to be regarded as anaplastic (WHO grade III). Alternatively one could argue that the behavior in this case was still more indolent than that typically observed in WHO grade III neoplasms and that the observed increased proliferative activity alone may not be a poor predictor of aggressive growth.. Nevertheless, we advocate maximal tumor resection for surgically accessible ganglioneurocytomas, as well as close imaging surveillance and clinical follow-up. In cases of STR or atypical features, adjuvant treatment with radiotherapy, and possibly chemotherapy, may be considered. Additional investigation into immunohistochemical and molecular markers that can refine pathological diagnosis of glioneuronal neoplasms is necessary to enable prospective evaluation of clinical outcomes and treatment effectiveness.

\section{References}

[1] Hassoun J, et al. Central neurocytoma. An electron-microscopic study of two cases. Acta Neuropathol. 1982; 56(2): 151-6. PMid: 7064664. http://dx.doi.org/10.1007/BF00690587

[2] Agarwal S, et al. Extraventricular neurocytomas: a morphological and histogenetic consideration. A study of six cases. Pathology. 2011; 43(4): 327-34. PMid: 21532524. http://dx.doi.org/10.1097/PAT.0b013e3283463f97

[3] Nishio SI Takeshita, Fukui M. Primary cerebral ganglioneurocytoma in an adult. Cancer. 1990; 66(2): 358-62. http://dx.doi.org/10.1002/1097-0142(19900715)66:2<358::AID-CNCR2820660226>3.0.CO;2-8

[4] Nishio S, et al. Cerebral neurocytoma. A new subset of benign neuronal tumors of the cerebrum. Cancer. $1992 ; 70(2): 529-37$. http://dx.doi.org/10.1002/1097-0142(19920715)70:2<529::AID-CNCR2820700225>3.0.CO;2-0

[5] Louis DN, et al. The 2007 WHO classification of tumours of the central nervous system. Acta Neuropathol. $2007 ; 114(2): 97-109$. PMid: 17618441. http://dx.doi.org/10.1007/s00401-007-0243-4

[6] Kurose A, et al. Ganglioneurocytoma: distinctive variant of central neurocytoma. Pathol Int. 2007; 57(12): 799-803. PMid: 17988282. http://dx.doi.org/10.1111/j.1440-1827.2007.02177.x

[7] Brat DJ, et al. Extraventricular neurocytomas: pathologic features and clinical outcome. Am J Surg Pathol. 2001; 25(10): 1252-60. PMid: 11688459. http://dx.doi.org/10.1097/00000478-200110000-00005

[8] Shidoh S, et al. Extraaxial neurocytoma in the skull base. Brain Tumor Pathol. 2011; 28(3): 273-7. PMid: 21562836. http://dx.doi.org/10.1007/s10014-011-0035-3

[9] Swinson BM, Friedman WA, Yachnis AT. Pontine atypical neurocytoma: case report. Neurosurgery. 2006; 58(5): E990; discussion E990.

[10] Sgouros S, Walsh AR, Barber P. Central neurocytoma of thalamic origin. Br J Neurosurg. 1994; 8(3): 373-6. PMid: 7946031. http://dx.doi.org/10.3109/02688699409029630

[11] Furtado A, et al. Comprehensive review of extraventricular neurocytoma with report of two cases, and comparison with central neurocytoma. Clin Neuropathol. 2010; 29(3): 134-40. PMid: 20423686. http://dx.doi.org/10.5414/NPP29134

[12] Biernat W, Zakrzewski K, Liberski PP. January 2000: 12 year old boy with recent onset seizures. Brain Pathol. 2000; 10(2): 313-4, 319. PMid: 10764051.

[13] Giangaspero F, et al. Extraventricular neoplasms with neurocytoma features. A clinicopathological study of 11 cases. Am J Surg Pathol. 1997; 21(2): 206-12. PMid: 9042288. http://dx.doi.org/10.1097/00000478-199702000-00011

[14] Ritz R, et al. Extraventricular neurocytoma presenting with intratumoral hemorrhage. Clin Neuropathol. 2005; 24(3): 101-5. PMid: 15943160. 
[15] Nishihara H, et al. A case of cerebral ganglioneuronal tumor in the parietal lobe of an adult. Brain Tumor Pathol. 2008; 25(1): 45-9. PMid: 18415666. http://dx.doi.org/10.1007/s10014-008-0229-5

[16] Tortori-Donati P, et al. Extraventricular neurocytoma with ganglionic differentiation associated with complex partial seizures. AJNR Am J Neuroradiol. 1999; 20(4): 724-7. PMid: 10319989.

[17] Yang GF, et al. Imaging findings of extraventricular neurocytoma: report of 3 cases and review of the literature. AJNR Am J Neuroradiol. 2009; 30(3): 581-5. PMid: 18842767. http://dx.doi.org/10.3174/ajnr.A1279

[18] Shin JH, et al. Neuronal tumors of the central nervous system: radiologic findings and pathologic correlation. Radiographics. 2002; 22(5): 1177-89. PMid: 12235346. http://dx.doi.org/10.1148/radiographics.22.5.g02se051177

[19] Moriguchi S, et al. Atypical extraventricular neurocytoma. Pathol Int. 2006; 56(1): 25-9. PMid: 16398676. http://dx.doi.org/10.1111/j.1440-1827.2006.01914.x

[20] Moller-Hartmann W, et al. Proton magnetic resonance spectroscopy of neurocytoma outside the ventricular region--case report and review of the literature. Neuroradiology. 2002; 44(3): 230-4. PMid: 11942378. http://dx.doi.org/10.1007/s002340100700

[21] Teo JG, et al. A distinctive glioneuronal tumor of the adult cerebrum with neuropil-like (including "rosetted") islands: report of 4 cases. Am J Surg Pathol. 1999; 23(5): 502-10. PMid: 10328080. http://dx.doi.org/10.1097/00000478-199905000-00002

[22] Mpairamidis E, et al. Extraventricular neurocytoma in a child: case report and review of the literature. J Child Neurol. 2009; 24(4): 491-4. PMid: 19339288. http://dx.doi.org/10.1177/0883073808324534

[23] Funato H, et al. Cystic ganglioneurocytoma outside the ventricular region. Acta Neuropathol. 1997; 94(1): 95-8. PMid: 9224537. http://dx.doi.org/10.1007/s004010050678

[24] Chou S, et al. Extraventricular neurocytoma with atypical features and ganglionic differentiation. J Clin Neurosci. 2010; 17(7): 920-2. PMid: 20399667. http://dx.doi.org/10.1016/j.jocn.2009.10.022

[25] Rades D, Schild SE, Fehlauer F. Prognostic value of the MIB-1 labeling index for central neurocytomas. Neurology. 2004; 62(6): 987-9. PMid: 15037708. http://dx.doi.org/10.1212/01.WNL.0000115392.21898.E3

[26] Ghosal N, et al. Atypical extraventricular neurocytoma: a rare and challenging case diagnosed on intraoperative cytology. Cytopathology. 2012; 23(4): 270-3. PMid: 21410797. http://dx.doi.org/10.1111/j.1365-2303.2011.00861.x

[27] Rades D, Fehlauer F, Schild SE. Treatment of atypical neurocytomas. Cancer. 2004; 100(4): 814-7. PMid: 14770439. http://dx.doi.org/10.1002/cncr.20032

[28] Myung JK, et al. Clinicopathological and genetic characteristics of extraventricular neurocytomas. Neuropathology. 2013; 33(2): 111-21. PMid: 22672632. http://dx.doi.org/10.1111/j.1440-1789.2012.01330.x

[29] Brandes AA, et al. Chemotherapy in patients with recurrent and progressive central neurocytoma. Cancer. 2000; 88(1): 169-74. http://dx.doi.org/10.1002/(SICI)1097-0142(20000101)88:1<169::AID-CNCR23>3.0.CO;2-7

[30] Dodds D, et al. Central neurocytoma: a clinical study of response to chemotherapy. J Neurooncol. 1997; 34(3): 279-83. PMid: 9258819. http://dx.doi.org/10.1023/A:1005713909836 